\title{
The glial cell response is an essential component of hypoxia-induced erythropoiesis in mice
}

\begin{abstract}
Alexander Weidemann,, ${ }^{1}$ Yann M. Kerdiles, ${ }^{1}$ Karl X. Knaup, ${ }^{2}$ Christopher A. Rafie, ${ }^{3}$ Adam T. Boutin, ${ }^{1}$ Christian Stockmann, ${ }^{1}$ Norihiko Takeda, ${ }^{1}$ Miriam Scadeng, ${ }^{4}$ Andy Y. Shih, ${ }^{3}$ Volker H. Haase, ${ }^{5}$ M. Celeste Simon, ${ }^{6}$ David Kleinfeld, ${ }^{3}$ and Randall S. Johnson ${ }^{1}$

1Division of Biology, University of California, San Diego, La Jolla, California, USA. ${ }^{2}$ Nikolaus-Fiebinger-Center for Molecular Medicine, Erlangen, Germany. ${ }^{3}$ Department of Physics and ${ }^{4}$ Center for Functional MRI, University of California, San Diego, La Jolla, California, USA. 5 Vanderbilt University Medical Center, Nashville, Tennessee, USA. ${ }^{6}$ Abramson Family Cancer Research Institute, University of Pennsylvania Cancer Center, Philadelphia, Pennsylvania, USA.
\end{abstract}

\begin{abstract}
A key adaptation to environmental hypoxia is an increase in erythropoiesis, driven by the hormone erythropoietin (EPO) through what is traditionally thought to be primarily a renal response. However, both neurons and astrocytes (the largest subpopulation of glial cells in the CNS) also express EPO following ischemic injury, and this response is known to ameliorate damage to the brain. To investigate the role of glial cells as a component of the systemic response to hypoxia, we created astrocyte-specific deletions of the murine genes encoding the hypoxia-inducible transcription factors HIF- $1 \alpha$ and HIF- $2 \alpha$ and their negative regulator von Hippel-Lindau (VHL) as well as astrocyte-specific deletion of the HIF target gene Vegf. We found that loss of the hypoxic response in astrocytes does not cause anemia in mice but is necessary for approximately $50 \%$ of the acute erythropoietic response to hypoxic stress. In accord with this, erythroid progenitor cells and reticulocytes were substantially reduced in number in mice lacking HIF function in astrocytes following hypoxic stress. Thus, we have demonstrated that the glial component of the CNS is an essential component of hypoxia-induced erythropoiesis.
\end{abstract}

\section{Introduction}

The erythropoietin (EPO) hormone is the chief regulator of red blood cell production in mammals, and its rate of synthesis is highly responsive to changes in physiologic oxygenation (1). Studies of this relationship between oxygen and red blood cell production date back to Viault's work at the end of the nineteenth century (2). Dissection of the mechanisms for induction of the Epo gene by low-oxygen conditions led to the discovery of a hypoxia responsive element (HRE) in the $3^{\prime}$ enhancer region of the gene; a binding site within the Epo gene was found for a family of transcription factors, which were subsequently termed hypoxia-inducible factors (HIFs) (3).

HIF is a heterodimeric DNA-binding complex composed of 2 basic helix-loop-helix proteins of the PAS family: the constitutive non-oxygen-responsive subunit HIF-1 $\beta$ (also termed ARNT) and 1 of either hypoxia-inducible $\alpha$-subunits, HIF- $1 \alpha$ or HIF- $2 \alpha$ (reviewed in refs. 4, 5). HIF- $\alpha$ subunits are rapidly degraded in normoxia but highly inducible by hypoxia. The interface between oxygen and the HIF- $\alpha$ subunits in normoxia is in part the hydroxylation of 2 prolyl residues in the oxygen-dependent degradation domain of the $\alpha$ subunits. HIF- $\alpha$ hydroxylation under normoxia regulates the interaction with the von Hippel-Lindau tumor suppressor protein ( $\mathrm{pVHL}$ ), which targets HIF- $\alpha$ for proteolysis by the ubiquitin-proteasome pathway (6).

EPO synthesis is only detectable in a small number of tissues, including the kidney, liver, and the CNS (reviewed in refs. 7, 8). The kidney produces a large fraction of the circulating EPO in adult mammals (9), and it is clear that nonrenal EPO does not compensate for the loss of renal EPO production in patients with chronic

Conflict of interest: The authors have declared that no conflict of interest exists. Citation for this article: J. Clin. Invest. 119:3373-3383 (2009). doi:10.1172/JCI39378. kidney disease. Thus, these patients rely on exogenous recombinant EPO for treatment of anemia.

A "hemopoietin" produced in the CNS was proposed by Carnot in 1906 (10); and indeed, EPO mRNA can be detected in the CNS (11). However, the physiology of cerebral EPO is incompletely understood, although some studies have shown it to play roles in neural development and neuroprotection (reviewed in ref. 12). Controversy exists, for example, as to whether EPO can cross the blood-brain barrier (BBB) $(12,13)$. This has led to a proposed paracrine rather than an endocrine role for the hormone in the CNS response to hypoxia (14).

In the CNS, both neurons $(15)$ and astrocytes $(16,17)$ are capable of EPO synthesis. Astrocytes make up the largest subpopulation of glial cells in the CNS and are a key factor in alleviating ischemic damage to neurons $(18,19)$. We therefore generated conditional deletions in astrocytes of the major factors that mediate hypoxic transcriptional response and regulate EPO, i.e., HIF-1 $\alpha$, HIF- $2 \alpha$, and VHL as well as the HIF target gene, which encodes the VEGF. Here, we show through loss-of-function mutations that the CNS is an essential part of a systemic erythropoietic response to hypoxia and demonstrate that the CNS directly participates in hypoxia-induced erythropoiesis.

\section{Results}

Recombination in murine, GFAP-expressing astrocytes. Mice that express Cre recombinase under an astrocyte-specific promoter (2) (glial fibrillary acidic protein [GFAP] with an internal ribosomal entry site [IRES] element for cotranslation of Cre and LacZ proteins [GFAPCre-IRES-LacZ]) were crossed with mice homozygous for conditional, loxP-flanked alleles of HIF-1 $\alpha$ (21), HIF- $2 \alpha(22)$, and VHL (23) (resulting in, e.g., GFAPCre $+/ \mathrm{VHL}^{+\mathrm{f} / \mathrm{f}}$ mice). PCR ampli- 
A
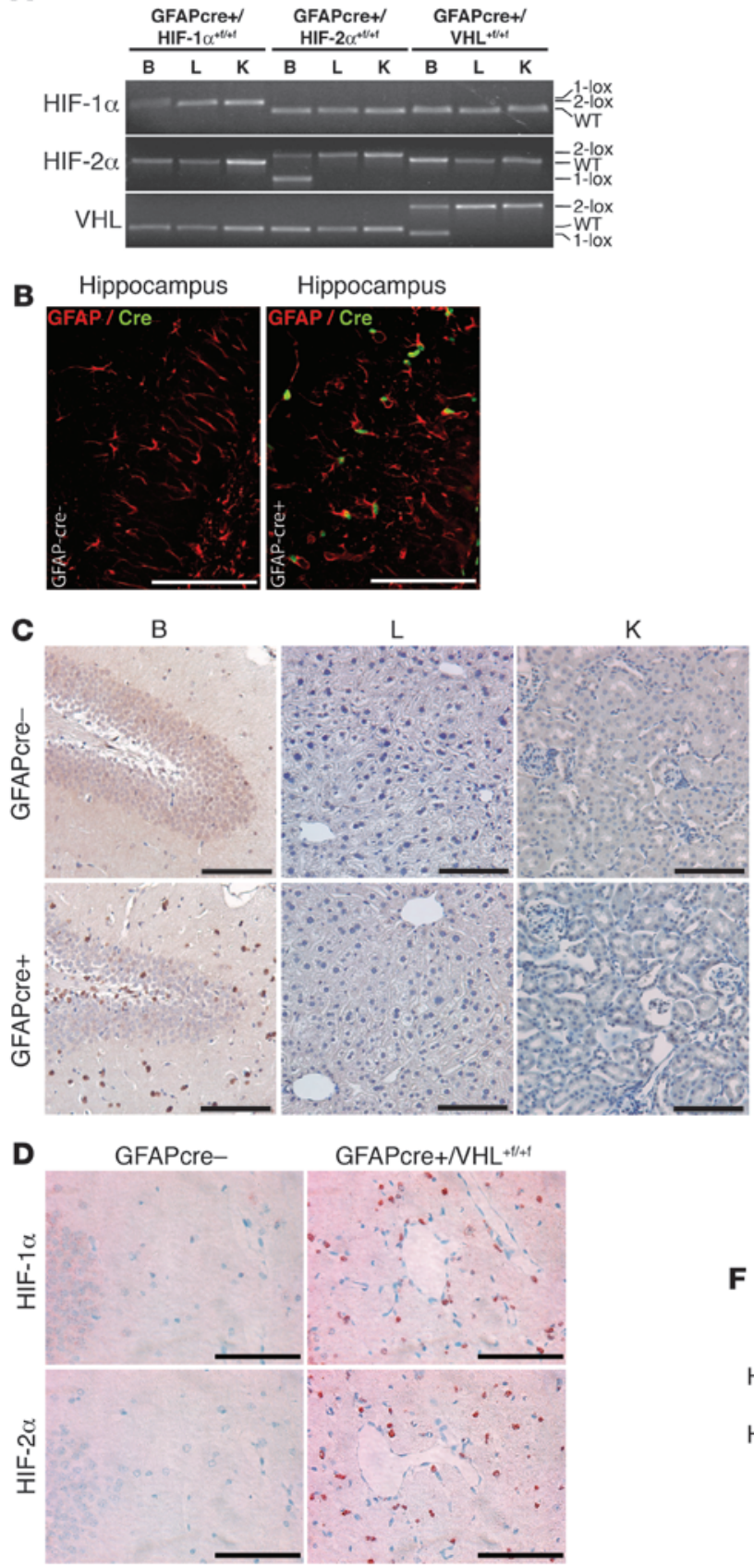

$\mathbf{F}$
$\mathbf{E}$

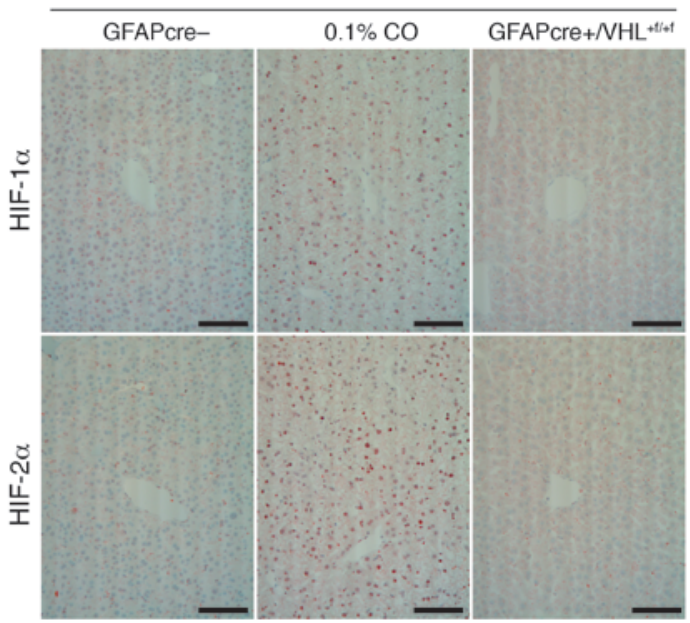

$\mathrm{K}$

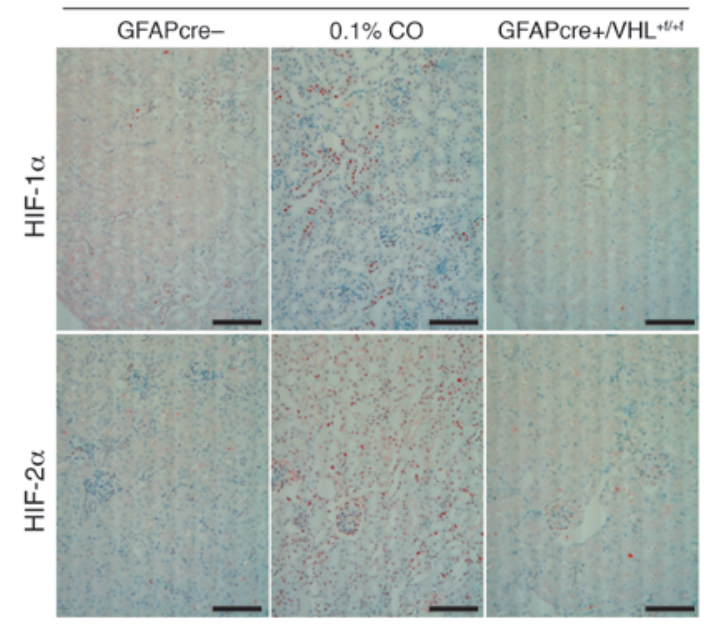

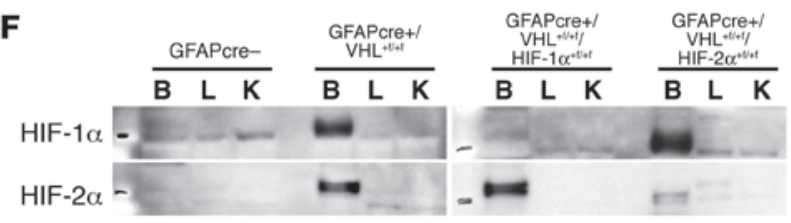

\section{Figure 1}

Generation of mice deficient for the genes encoding HIF-1 $\alpha$, HIF-2 $\alpha$, and VHL in astrocytes. (A) Genomic PCR analysis of DNA isolated from brain (B), liver (L), and kidney (K) with primers amplifying the conditional (2-lox), the recombined (1-lox) and the WT allele. Recombination of the conditional allele was detected in brain, but not in liver or kidney, in GFAPCre+/HIF-1 $\alpha^{+f /+f}$, GFAPCre $+/ \mathrm{HIF}-2 \alpha^{+f /+f}$, and GFAPCre $+/ \mathrm{VHL} \mathrm{L}^{+\mathrm{f} / \mathrm{f}}$ mice, respectively (representative photograph). (B) Cre protein colocalizes with the astrocyte marker GFAP in the hippocampus of adult GFAPCre-positive animals (representative photographs). Scale bars: $100 \mu \mathrm{m}$. (C) Cre protein is expressed in brains of GFAPCre-positive animals, but not in liver and kidney (representative photographs). Scale bars: $100 \mu \mathrm{m}$. (D) Both HIF-1 $\alpha$ and HIF-2 $\alpha$ protein are not detectable in brain sections of GFAPCre-negative animals in normoxia. In contrast, both isoforms are strongly induced in brains of normoxic GFAP$\mathrm{Cre}+/ \mathrm{VHL}^{+\mathrm{f}+\mathrm{f}}$ mice (representative photographs). Scale bars: $100 \mu \mathrm{m}$. (E) HIF- $\alpha$ isoforms are not stabilized in livers and kidneys of GFAP$\mathrm{Cre}+/ \mathrm{VHL}^{+\mathrm{f} / \mathrm{f}}$ animals. WT animals treated with $0.1 \%$ carbon monoxide $(\mathrm{CO})$ are shown as positive controls (representative photographs). Scale bars: $100 \mu \mathrm{m}$. (F) Immunoblots show the normoxic induction of both HIF- $\alpha$ isoforms in whole-brain lysates, but not in liver or kidney of

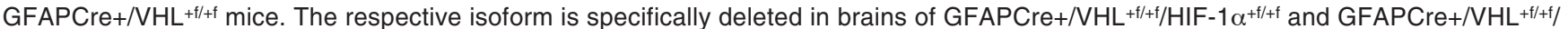
HIF- $2 \alpha^{+f /+f}$ double-knockout animals. 

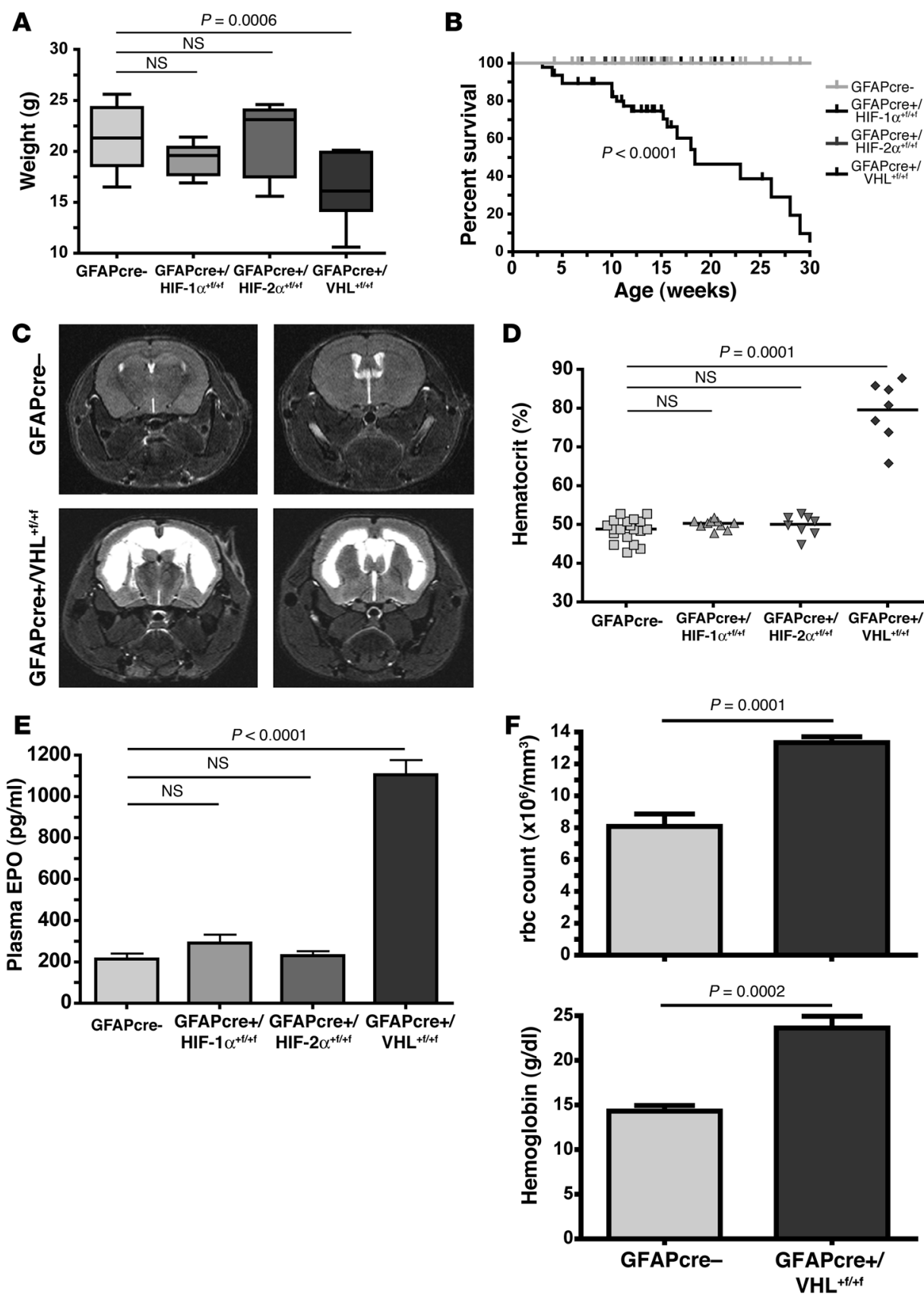

\section{Figure 2}

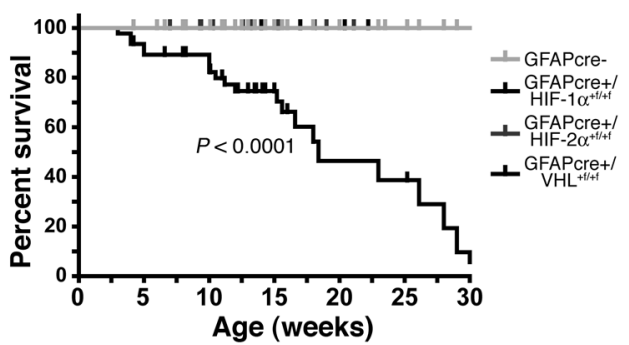

D

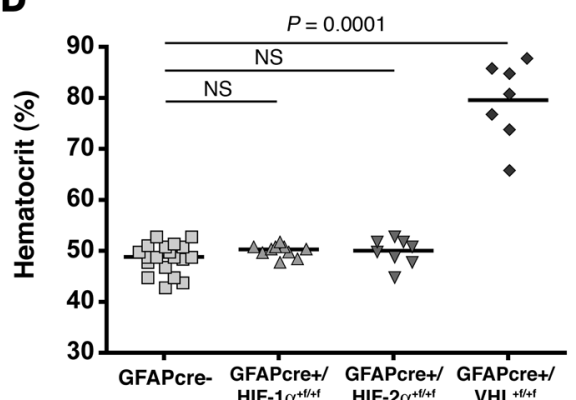

Knockout of VHL in astrocytes reduces survival, induces hydrocephalus, and leads to severe erythrocytosis in mice. (A) The weight of 6-week-old GFAPCre+/VHL ${ }^{+f /+f}$ animals $(n=8)$ is significantly less than that of control (GFAPCre-; $n=23$ ), GFAPCre+/HIF$1 \alpha^{+f /+f}(n=9)$, and GFAPCre+/HIF$2 \alpha^{+f /+f}(n=8)$ animals. Data represent median and interquartile ranges. (B) Survival is significantly reduced to 18.4 weeks in GFAPCre+/VHL ${ }^{+f /+f}(n=45)$ compared with control animals (GFAPCre-; $n=46$ ). It is normal in GFAP$\mathrm{Cre}+/ \mathrm{HIF}-1 \alpha^{+f+f}(n=25)$ and in GFAP$\mathrm{Cre}+/ \mathrm{HIF}-2 \alpha^{+f /+f}$ mice $(n=57)$. Data represent median survival (weeks). (C) GFAPCre+/VHL ${ }^{+f /+f}$ mice (lower panel) develop severe hydrocephaly (representative T2 weighed fMRI photographs; cerebrospinal fluid appears white). (D) Hematocrits at the age of 10 weeks are not different in control (GFAPCre-; $n=19$ ), GFAPCre+/HIF$1 \alpha^{+f /+f}(n=10)$, and GFAPCre+/HIF$2 \alpha^{+f /+f}$ animals $(n=8)$. In contrast, GFAPCre+/VHL ${ }^{+f /+f}$ mice $(n=7)$ exhibit a striking elevation of the hematocrit. (E) Plasma EPO levels in GFAPCre+/ $\mathrm{VHL}^{+\mathrm{f}+\mathrm{f}}$ animals $(n=12)$ are significantly increased compared with those in control mice (GFAPCre-; $n=34$ ). No difference from WT plasma EPO levels is detected in GFAPCre+/HIF- $1 \alpha^{+f /+f}$ $(n=10)$ and GFAPCre+/HIF- $2 \alpha^{+f /+f}$ mice $(n=6)$. Data represent mean + SEM. (F) Red blood cell count (upper panel) and hemoglobin concentration (lower panel) are both significantly higher in GFAPCre+/VHL ${ }^{+1 /+f}(n=6)$ than in control animals (GFAPCre-; $n=5$ ), which indicates pathological erythrocytosis. Data represent mean + SEM . fication of genomic DNA of brain, liver and kidney shows DNA is recombined, resulting in deletion in 3 loci (Hifla, Epas1, and Vhl) in brain-derived DNA of GFAPCre+ animals but not in kidney- or liver-derived DNA (Figure 1A). Cre recombinase protein expression mimics astrocyte distribution (Supplemental Figure 1A; supplemental material available online with this article; doi:10.1172/ JCI39378DS1) and colocalizes to GFAP (Figure 1B) but not to the neuronal marker NeuN (Supplemental Figure 1B). In contrast, nonastrocytic tissues do not express Cre recombinase in GFAPCrepositive animals (Figure 1B).

In addition, loss of the negative regulator of the HIF- $\alpha$ genes, VHL, resulted in detectable expression of both HIF- $1 \alpha$ and HIF- $2 \alpha$ protein in normoxic brains as determined immunohistologically
(Figure 1D) and by immunoblot (Figure 1F). As expected, HIF- $\alpha$ isoforms are not stabilized in livers or kidneys of GFAPCre+/ $\mathrm{VHL}^{+\mathrm{f} / \mathrm{f}}$ mice and are thus undetectable in tissue sections (Figure $1 \mathrm{E}$ ) and in immunoblots of whole-organ lysates (Figure 1F). Under control conditions, neither HIF- $\alpha$ isoform is detectable in substantial amounts in WT animals.

Severe pathology due to loss of VHL in astrocytes. Mice harboring conditional deletions of HIF- $1 \alpha$, HIF- $2 \alpha$, or VHL in astrocytes are all born at expected ratios and are viable at birth (data not shown). However, animals with deletion of VHL in astrocytes fail to thrive and are significantly smaller than GFAPCre-negative, HIF- $1 \alpha$, or HIF- $2 \alpha$ conditional knockout animals at the age of 6 weeks (GFAPCre-negative: $21.16 \pm 0.7 \mathrm{~g}$ vs. GFAPCre $+/ \mathrm{VHL}^{+\mathrm{f} / \mathrm{f}}: 17.13 \pm 0.9 \mathrm{~g}$; 
Figure 2A and Supplemental Figure 1C). Both HIF-1 $\alpha$ and HIF-2 $\alpha$ conditional knockout animals have a normal life span and normal fertility and show no obvious neurologic defects (Figure $2 \mathrm{~B}$ and data not shown). In GFAPCre $+/ \mathrm{VHL}^{+\mathrm{f} / \mathrm{f}}$ animals, however, survival is significantly reduced relative to WT controls (Figure $2 \mathrm{~B}$ ). They exhibit severe locomotive defects, a dome-shaped skull (Supplemental Figure 1C), increased permeability of the BBB (Supplemental Figure 1D), and hydrocephalus, as assessed by functional MRI (fMRI) (Figure 2C). No signs of increased ventricular space were found in fMRI analyses of GFAPCre + HIF- $1 \alpha^{+f /+f}$ and GFAPCre + / HIF- $2 \alpha^{+\mathrm{f} / \mathrm{f}}$ mice (data not shown).

Surprisingly, it was found that the hematocrit is dramatically elevated (to $79.6 \% \pm 3 \%$ in 10 -week-old GFAPCre $+/ \mathrm{VHL}^{+\mathrm{f} /+\mathrm{f}}$ mice) when VHL mutants are compared with control animals $(48.5 \% \pm 0.8 \%$; Figure $2 \mathrm{D})$. In contrast, hematocrits of GFAP$\mathrm{Cre}+/ \mathrm{HIF}-1 \alpha^{+\mathrm{f} /+\mathrm{f}}$ and GFAPCre $+/ \mathrm{HIF}-2 \alpha^{+\mathrm{f} /+\mathrm{f}}$ mice are not significantly different from those of WT mice.

The increased hematocrit found in VHL conditionally null mice is driven by elevated EPO plasma levels: deletion of VHL in astrocytes increases the plasma EPO levels from $213.3 \pm 27.9$ $\mathrm{pg} / \mathrm{ml}$ in WT controls to $1106 \pm 72.4 \mathrm{pg} / \mathrm{ml}$ in GFAPCre+/ $\mathrm{VHL}^{+\mathrm{f} / \mathrm{+f}}$ mice (Figure 2E). Reticulocyte numbers are significantly increased in GFAPCre ${ }^{+} / \mathrm{VHL}^{+\mathrm{f} / \mathrm{f}}$ animals (data not shown), as are the red blood cell numbers $\left(8.078 \pm 0.8 \times 10^{6} / \mathrm{mm}^{3}\right.$ vs. $13.33 \pm$ $\left.0.4 \times 10^{6} / \mathrm{mm}^{3}\right)$ and hemoglobin concentrations $(14.32 \pm 0.6 \mathrm{~g} / \mathrm{dl}$ vs. $23.63 \pm 1.3 \mathrm{~g} / \mathrm{dl}$; Figure $2 \mathrm{~F}$ ).

Taken together, these data show that deletion of VHL in astrocytes induces a severe pathology, with reduced survival, hydrocephaly, and excessive erythrocytosis. None of these phenotypes were detected in mice lacking HIF- $1 \alpha$ or HIF- $2 \alpha$ in astrocytes.

Excessive erythrocytosis after loss of VHL is dependent on HIF-2 $\alpha$ overexpression in astrocytes. A number of studies have shown that in the context of loss of VHL function, HIF- $2 \alpha$ becomes the dominant HIF- $\alpha$ isoform (24-27). To investigate which HIF- $\alpha$ isoform is the major determinant of phenotypic changes in the tissue-specific deletion of VHL in astrocytes, deletions of VHL and HIF- $1 \alpha$ $\left(\right.$ GFAPCre $\left.^{+} / \mathrm{VHL}^{+\mathrm{f} / \mathrm{+}} / \mathrm{HIF}-1 \alpha^{+\mathrm{f} / \mathrm{f}}\right)$ and VHL and HIF- $2 \alpha$ (GFAP-

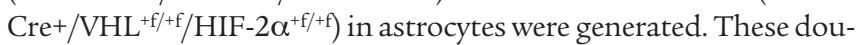
ble mutants are viable, but removal of VHL and HIF- $1 \alpha$ in astrocytes does not improve survival rate relative to VHL deletion alone and in fact significantly shortens it, to 16.1 weeks (Figure $3 \mathrm{~A}$ ). In contrast, loss of VHL and HIF-2 $\alpha$ gives rise to mice with a normal life span (Figure 3A), and these mice have growth curves indistinguishable from those of WT littermates (data not shown).

The hematocrit at the age of 12 weeks in GFAPCre $+/ \mathrm{VHL}^{+\mathrm{f} / \mathrm{f}}$ animals was $81.7 \% \pm 1 \%$; this was significantly elevated in GFAP$\mathrm{Cre}^{+} / \mathrm{VHL}^{+\mathrm{f} / \mathrm{f}} / \mathrm{HIF}-1 \alpha^{+\mathrm{f} /+\mathrm{f}}$ mutants (to $86.9 \% \pm 0.8 \%$; Figure $3 \mathrm{~B}$ ). In contrast, the hematocrits of GFAPCre $+/ \mathrm{VHL}^{+\mathrm{f} / \mathrm{f}} / \mathrm{HIF}-2 \alpha^{+\mathrm{f} /+\mathrm{f}}$ were not significantly different from those of control mice $(48.8 \% \pm 0.7 \%)$. Augmented erythropoiesis and erythrocytosis also had profound effects on other organs: the spleen (a site of extramedullary erythropoiesis in the mouse; ref. 28) and the

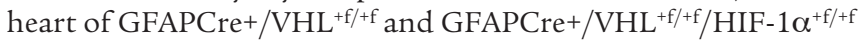
animals were significantly enlarged compared with those organs

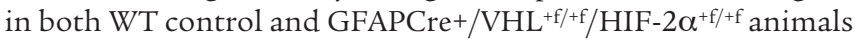
(Supplemental Figure 1E). The presence of hydrocephaly, already detectable in 3-week-old mice, was also clearly HIF-2 $\alpha$ dependent (Supplemental Figure 1F), further supporting the notion that HIF- $2 \alpha$ is the critical determinant of the phenotype induced by deletion of VHL in astrocytes.

\section{Figure 3}

HIF-2 $\alpha$-dependent EPO overexpression in astrocytes drives erythrocytosis in GFAPCre $+/ \mathrm{VHL}^{+f /+f}$ animals and suppresses renal EPO. (A) Survival of GFAPCre+/VHL $+\mathrm{f} /+\mathrm{f} / \mathrm{HIF}-1 \alpha^{+f /+f}$ animals $(n=55)$ is reduced compared with GFAPCre+ $/ \mathrm{VHL}^{+t /+f}$ mice $(n=45)$. GFAPCre $+/ \mathrm{VHL}^{+t /+f /}$ HIF-2 $\alpha^{+f /+f}$ mice $(n=59)$ have a normal life span. Data represent mean survival (weeks). (B) At 12 weeks, hematocrits of both GFAPCre+/ $\mathrm{VHL}^{+f /+f}(n=7)$ and GFAPCre+/VHL ${ }^{+f /+f / H I F-1} \alpha^{+f /+f}$ mice $(n=11)$ are significantly elevated (GFAPCre-; $n=20$ ). GFAPCre+/VHL $+f /+t / H I F-$ $2 \alpha^{+t /+f}$ mice $(n=9)$ have a normal hematocrit. Data represent mean. (C) Hematocrit development: increased hematocrit in GFAPCre $+/ \mathrm{VHL}^{+\mathrm{f} / \mathrm{f}}$ mice from the age of 4 weeks and from 3 weeks in GFAPCre $+/ \mathrm{VHL}^{+t /+f /}$ HIF- $1 \alpha^{+f /+f}$ mutants compared with WT. Hematocrits of GFAPCre+l

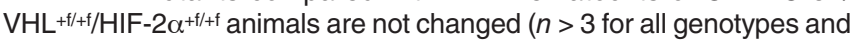
time points). Data represent mean \pm SEM. ${ }^{*} P<0.05$ vs. WT; ${ }^{\#} P<0.05$ vs. GFAPCre+/VHL ${ }^{+f /+f}$. (D) GFAPCre $+/ \mathrm{VHL}^{+f /+f}(n=12)$ and GFAP$\mathrm{Cre}+/ \mathrm{VHL}+\mathrm{f} / \mathrm{f} / \mathrm{HIF}-1 \alpha^{+f /+f}$ mice $(n=6)$ have significantly higher plasma EPO concentrations compared with controls (GFAPCre-; $n=30$ ). Plasma EPO levels in GFAPCre+/VHL ${ }^{+f /+f / H I F-2} \alpha^{+f / f}$ animals $(n=9)$ are not elevated. (E) EPO mRNA is upregulated in brains of GFAPCre+/NHL ${ }^{+f /+f}$ $(n=10)$ and GFAPCre+/VHL $+f /+f / H I F-1 \alpha^{+f /+f}$ mice $(n=6)$ compared with controls (GFAPCre-; $n=9$ ). (F) Kidney EPO mRNA is suppressed in GFAPCre+/VHL ${ }^{+f /+f}$ animals $(n=8)$ relative to controls (GFAPCre-; $n=12$ ) and is not detectable in 4 of 5 kidneys of GFAPCre $+/ \mathrm{VHL}^{+f+t / H I F-}$ $1 \alpha^{+f /+f}$ mice. In kidneys of GFAPCre+/VHL ${ }^{+f /+t / H I F-2} \alpha^{+f /+f}$ mice $(n=6)$, kidney EPO mRNA expression is normal. (G) Hepatic EPO mRNA expression in GFAPCre+/VHL ${ }^{+/+f}(n=5)$ and GFAPCre $+/ \mathrm{VHL}^{+f /+f / H I F-}$ $2 \alpha^{+f /+f}$ mice $(n=5)$ and controls (GFAPCre-; $n=14$ ) does not differ, but is higher in GFAPCre+/VHL $+f /+f / H I F-1 \alpha^{+f /+f}$ animals $(n=5)$. Rel, relative. (D-G) Data represent mean + SEM, Mann-Whitney $U$ test. (H) No HIF- $\alpha$ activation in livers of GFAPCre+/VHL $+1++/ / H I F-1 \alpha^{+/ /+f}$ animals. Representative photograph. Scale bars: $100 \mu \mathrm{m}$.

Blood analyses indicated that hematocrits began to rise after 3 weeks of age and reached peak levels at 5 weeks in GFAPCre + /

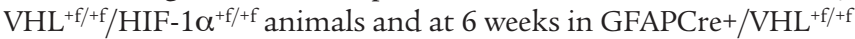
mice (Figure $3 \mathrm{C}$ ). Plasma concentration of EPO in adult animals was not significantly different in GFAPCre $+/ \mathrm{VHL}^{+\mathrm{f} /+\mathrm{f}} / \mathrm{HIF}-1 \alpha^{+\mathrm{f} / \mathrm{f}}$ and in GFAPCre ${ }^{+} / \mathrm{VHL}^{+\mathrm{f} / \mathrm{f}}$ animals $(1154 \pm 210.9 \mathrm{pg} / \mathrm{ml}$ vs. $1077 \pm 94.6 \mathrm{pg} /$ $\mathrm{ml}$; Figure 3D), but plasma EPO in GFAPCre $+/ \mathrm{VHL}^{+\mathrm{f} / \mathrm{f}} / \mathrm{HIF}-2 \alpha^{+\mathrm{f} / \mathrm{f}}$ mice was reduced to the levels seen in WT control animals.

Increased EPO expression in astrocytes causes suppression of renal but not hepatic EPO $m R N A$ levels. Deletion of VHL in astrocytes dramatically increased cerebral EPO mRNA levels relative to those found in control animals $(1801 \pm 208.3$-fold; Figure 3E). This increase in EPO expression was almost eliminated with a concurrent deletion of HIF- $2 \alpha$, but not HIF-1 $\alpha$ (Figure $3 \mathrm{E}$ ). In animals lacking VHL or both VHL and HIF-1 $\alpha$ in astrocytes, EPO mRNA expression in the kidney was suppressed to almost undetectable levels (Figure $3 \mathrm{~F})$. In contrast, EPO expression was not significantly different in kidneys of GFAPCre $+/ \mathrm{VHL}^{+\mathrm{f} / \mathrm{f}} / \mathrm{HIF}-2 \alpha^{+\mathrm{f} /+\mathrm{f}}$ compared with control animals (1.393 \pm 0.4 -fold vs. $1.128 \pm 0.1$-fold). Intriguingly, hepatic EPO expression was not suppressed; while it was not significantly different from WT levels in GFAPCre $+/ \mathrm{VHL}^{+\mathrm{f} /+\mathrm{f}}$ and GFAPCre $+/ \mathrm{VHL}^{+\mathrm{f} /+\mathrm{f}} / \mathrm{HIF}-2 \alpha^{+\mathrm{f} /+\mathrm{f}}$ mice, it was somewhat elevated

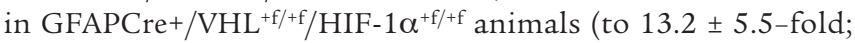
Figure $3 \mathrm{G}$ ). This indicates that polycythemic feedback inhibition of EPO synthesis was not acting on the liver. Ectopic expression of HIF- $1 \alpha$ and HIF- $2 \alpha$ was not detectable in livers of GFAPCre+/ $\mathrm{VHL}^{+\mathrm{f} / \mathrm{f}} / \mathrm{HIF}-1 \alpha^{+\mathrm{f} /+\mathrm{f}}$ mice (Figure $3 \mathrm{H}$ ).

Deletion of astrocytic expression of VEGF can act to suppress nonhematologic phenotypes induced by loss of VHL. Deletion of VHL in astrocytes 
A

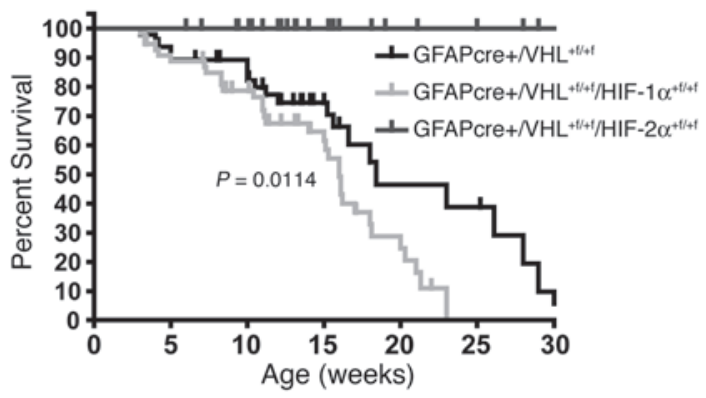

C
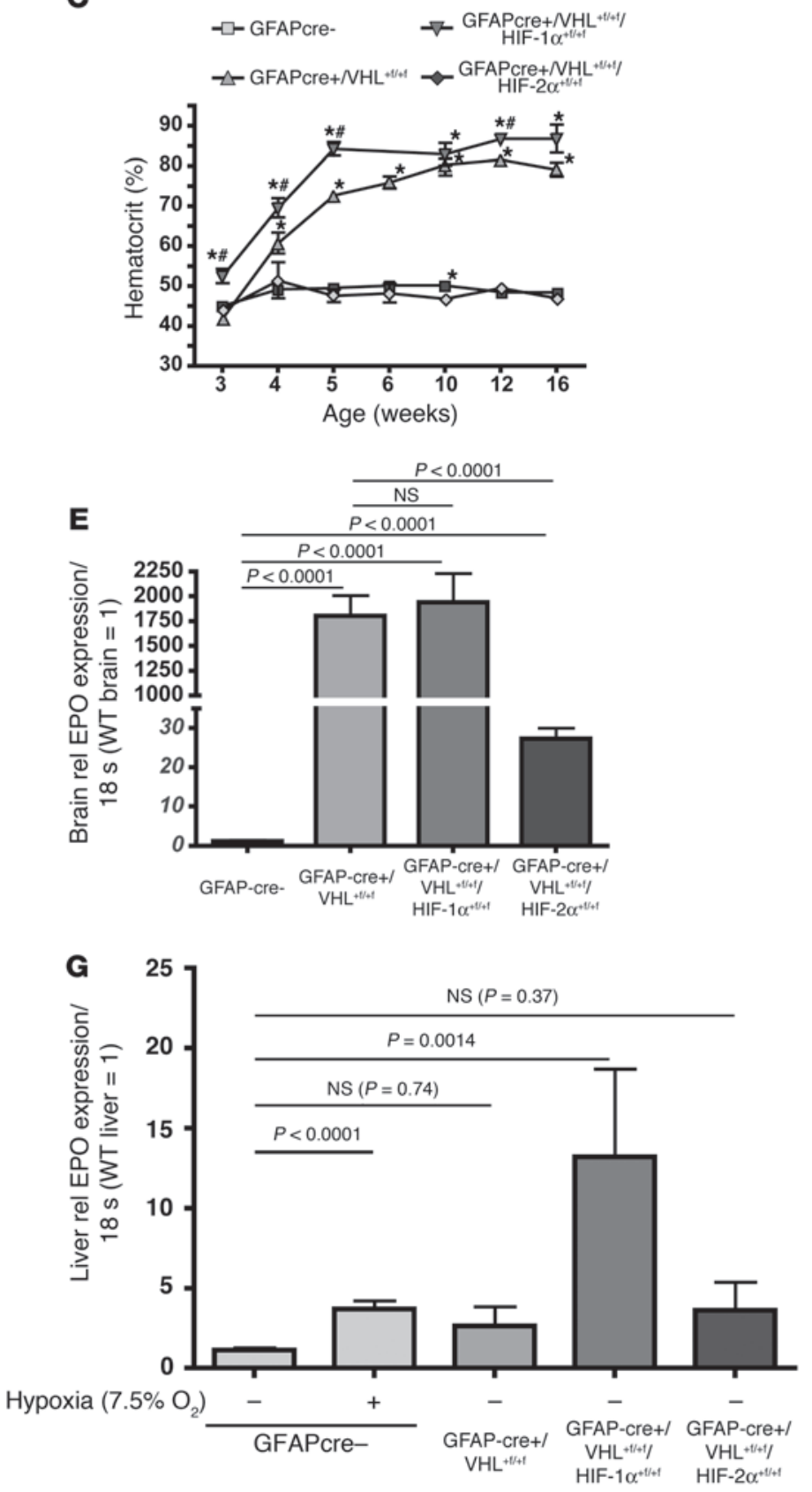
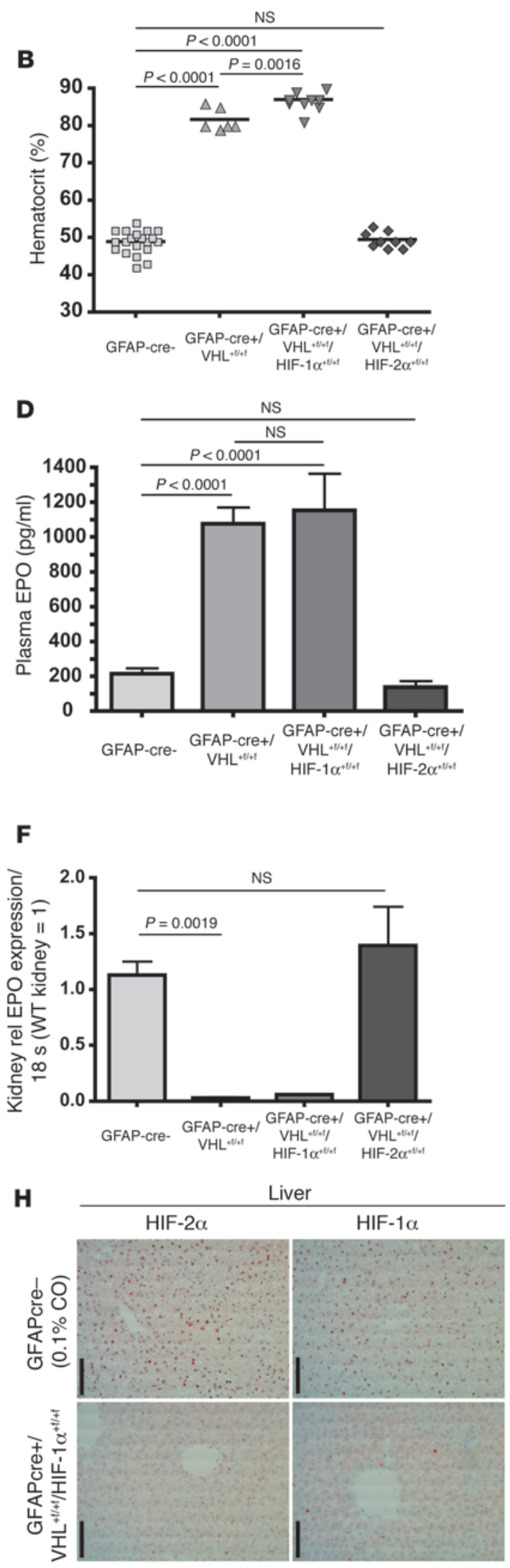
A

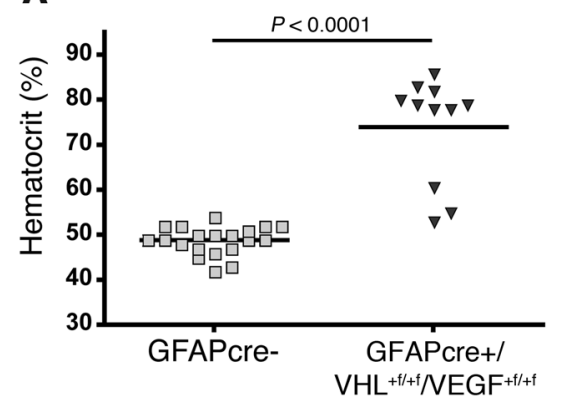

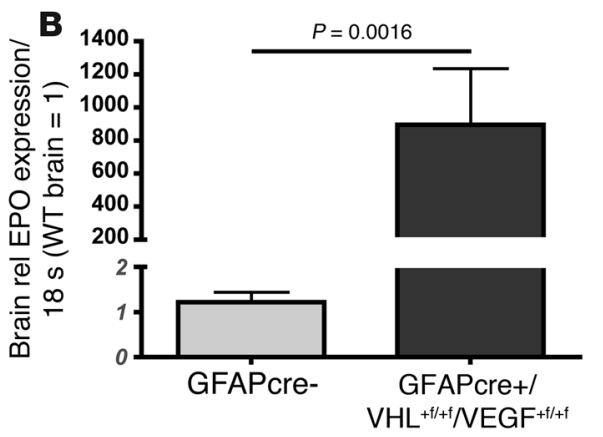

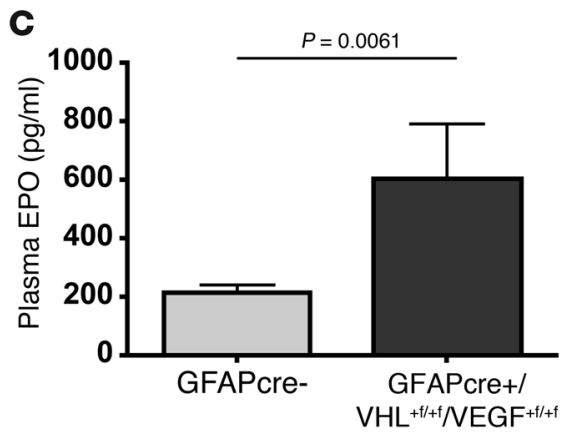

Figure 4

Deletion of VEGF in astrocytes does not suppress hematologic phenotype induced by loss of VHL. (A) The hematocrit in GFAPCre+/VHL ${ }^{+i /+f /}$ VEGF $+f /+f$ animals $(n=11)$ is significantly elevated compared with that of control animals $(n=20)$ at the age of 12 weeks. Data represent mean + SEM; Mann-Whitney test. (B) EPO mRNA expression in brains of GFAPCre+/VHL $+f+f / V E G F+f /+f$ animals $(n=5)$ is significantly higher than in control animals (GFAPCre-; $n=7$ ). Data represent mean + SEM; Mann-Whitney test. (C) Accordingly, plasma EPO levels are increased in GFAPCre+/VHL ${ }^{+f /+f / V E G F}{ }^{+f /+f}$ mice $(n=6)$ compared with controls (GFAPCre-; $n=30$ ). Data represent mean + SEM; Mann-Whitney test.

not only induced EPO, but also the HIF target gene VEGF, in a HIF- $2 \alpha$-dependent fashion (Supplemental Figure 2C); this was correlated with an expansion of vessels in the CNS (Supplemental Figure 2D). The vessels in the CNS of GFAPCre $+/ \mathrm{VHL}^{+\mathrm{f} / \mathrm{f}}$ and

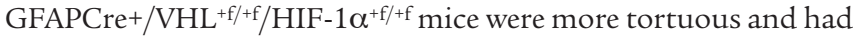
an increased diameter; the blood flow velocity through them was consequently reduced (Supplemental Figure 2, E and F). Mutants with deletions of VHL and VEGF (29) in astrocytes were generated to determine whether loss of VEGF suppressed the phenotypic effects of VHL deletion. The mean survival of GFAPCre $+/ \mathrm{VHL}^{+\mathrm{f} / \mathrm{f}} /$ $\mathrm{VEGF}^{+\mathrm{f} / \mathrm{+f}}$ animals was prolonged to 22.6 weeks, but was still significantly shorter than that of WT animals (Supplemental Figure 3A). They exhibited a high hematocrit (Figure 4A), with elevated EPO mRNA in the brain (Figure 4B) and high plasma EPO concentrations (Figure 4C). MRI imaging showed that GFAPCre $+/ \mathrm{VHL}^{+\mathrm{f} / \mathrm{f}}$ / $\mathrm{VEGF}^{+\mathrm{f} / \mathrm{+f}}$ mice did not develop hydrocephaly; however, the brains appeared smaller in size than those of GFAPCre-negative littermates (Supplemental Figure 3B). Thus, concomitant deletion of VEGF in the VHL-null background in astrocytes suppressed some of the phenotypic effects of VHL loss, although this did not affect the hematological changes observed in these animals.

Targeted deletion of HIF-2 $\alpha$ in astrocytes reduces systemic erythropoietic response to acute bypoxia. The data described above indicate that deletion of VHL in astrocytes causes excessive systemic erythropoiesis, driven by HIF- $2 \alpha$-dependent EPO expression in the CNS. This suggests a potential role for astrocytes in erythropoiesis. However, secondary effects associated with the pathology of VHL deletion in the CNS might influence the erythropoietic phenotype observed. To investigate the systemic importance of astrocyte HIF function independently, we examined erythropoietic stress responses to hypoxia in GFAPCre + HIF- $1 \alpha^{+\mathrm{f} /+\mathrm{f}}$, GFAPCre $+/ \mathrm{HIF}-2 \alpha^{+\mathrm{f} / \mathrm{f}}$, and

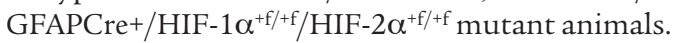

Exposure of WT mice to $7.5 \%$ oxygen for 10 hours induced EPO mRNA expression $16.75 \pm 2.7$-fold in the brain relative to levels seen at normoxia (1.63 \pm 0.6 -fold; Figure $5 \mathrm{~A})$. Deletion of HIF- $1 \alpha$ in astrocytes did not significantly change the hypoxic EPO induction (to $18.17 \pm 2.6$-fold); however, we found that in GFAPCre+/ $\mathrm{HIF}-2 \alpha^{+\mathrm{f} / \mathrm{f}}$ mice, the hypoxia-induced increase in EPO mRNA levels was significantly reduced, to $2.82 \pm 0.3$-fold, which indicates that the hypoxic induction is critically dependent on the presence of HIF-2 $\alpha$. It also demonstrates that the majority of EPO mRNA response in the CNS was due to HIF- $2 \alpha$-driven activation of EPO synthesis in astrocytes.

Deletion of both HIF- $1 \alpha$ and HIF- $2 \alpha$ together in astrocytes further reduced brain EPO mRNA levels significantly, both in normoxia (to $0.29 \pm 0.03$-fold) and in hypoxia (to $1.78 \pm 0.2$-fold; Figure $5 \mathrm{~A}$ ). This argues that HIF-1 $\alpha$ does participate in regulation of EPO synthesis in this tissue when HIF- $2 \alpha$ is absent.

Plasma EPO concentrations were also significantly reduced, by about $35 \%$, in hypoxic GFAPCre + HIF- $2 \alpha^{+\mathrm{f} /+\mathrm{f}}$ animals when compared with EPO detected in plasma of hypoxic WT control mice $(733.6 \pm 108 \mathrm{pg} / \mathrm{ml}$ vs. $1138 \pm 121.5 \mathrm{pg} / \mathrm{ml}$; Figure 5B). Animals with astrocytic deletions of both HIF- $1 \alpha$ and HIF- $2 \alpha$ had an even greater reduction in plasma EPO following hypoxia, with amounts that were approximately half those seen in hypoxic, WT controls $(555.7 \pm 81.2 \mathrm{pg} / \mathrm{ml}$; Figure $5 \mathrm{~B})$.

These data, coupled to an absence of changes in renal or hepatic EPO response in these animals in hypoxia (Figure 5, C and D), indicate that no renal or hepatic compensation occurs in mutant animals and thus that the diminished EPO originating from HIF- $\alpha-$ null astrocytes is directly responsible for reducing systemic circulating EPO protein levels.

Loss of HIF-2 $\alpha$ in astrocytes inbibits systemic response to acute blood loss. Bleeding represents another stress to the erythropoietic system that is compensated for by an acute induction of EPO expression, followed by a burst of erythropoiesis. To determine the role of CNS-induced response to blood loss, phlebotomy was performed to lower animal hematocrits by approximately $10 \%$. Consistent with the effects seen after hypoxic exposure, the plasma EPO concentration 14 hours after bleeding was significantly reduced in GFAPCre $+/ \mathrm{HIF}-2 \alpha^{+\mathrm{f} /+\mathrm{f}}$ mice compared with WT littermates $(833.0 \pm 148.7 \mathrm{pg} / \mathrm{ml}$ vs. $1303 \pm 124.1 \mathrm{pg} / \mathrm{ml}$; Figure $6 \mathrm{~A})$; this difference disappears after 72 hours, indicating that after a diverse pathophysiological stimulus, astrocyte-derived EPO is necessary for an acute systemic response.

The principal biological function of EPO is the inhibition of apoptosis of erythroid progenitor cells, which in turn facilitates their proliferation and differentiation (1). To determine the functional role of astrocyte-derived EPO, proliferation of erythroid progenitor cells (detected by the cell-surface markers CD71 and 

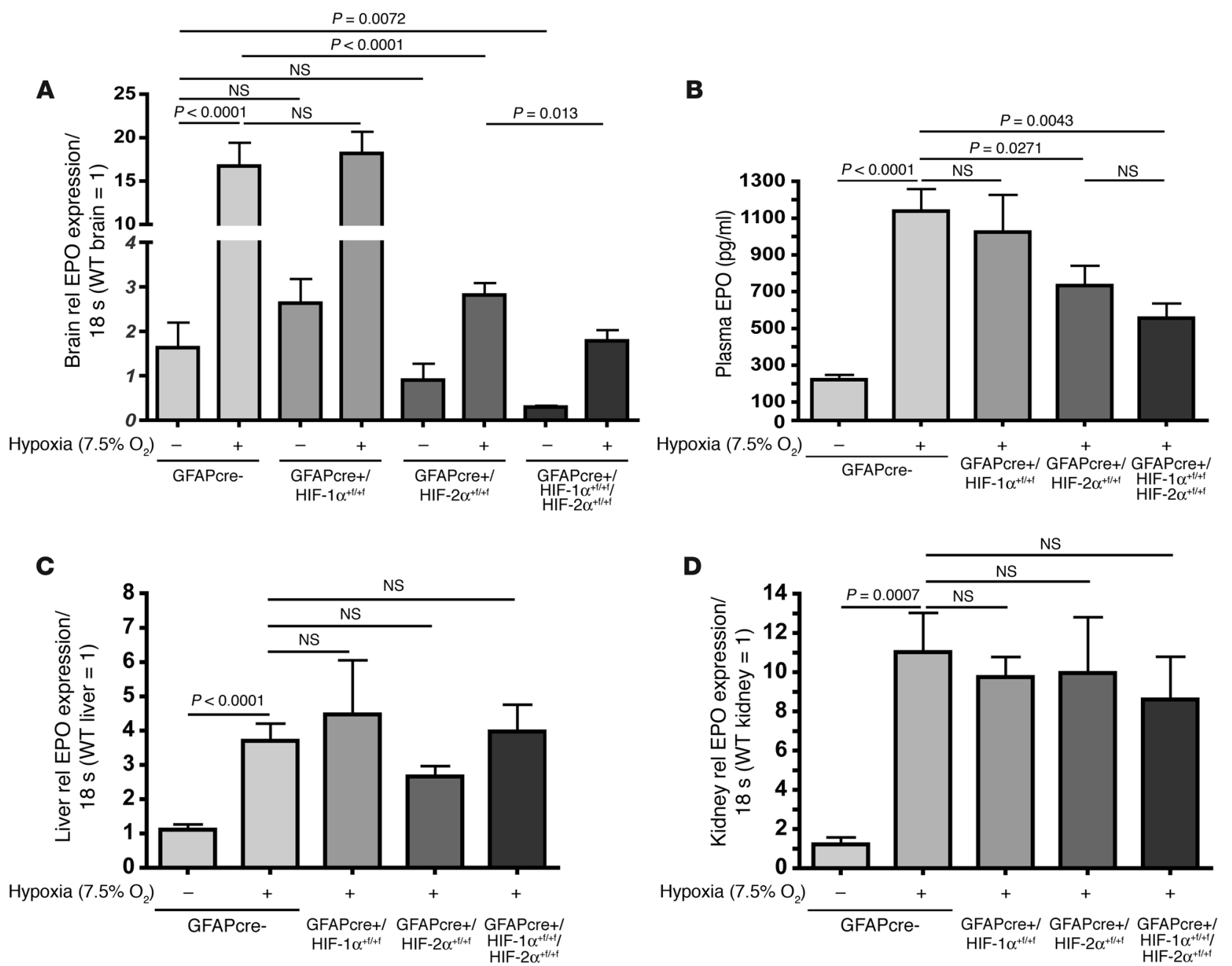

Figure 5

Targeted deletion of HIF-2 $\alpha$ in astrocytes reduces systemic plasma EPO concentration after acute hypoxia. (A) Cerebral EPO mRNA expression in hypoxia is significantly upregulated in control animals (GFAPCre-; $n=20)$ compared with normoxia $(n=12)$. The hypoxic upregulation is significantly reduced in GFAPCre+/HIF-2 $\alpha^{+f /+f}(n=11)$ but not in GFAPCre+/HIF-1 $\alpha^{+f /+f}$ animals $(n=10)$. Hypoxic EPO mRNA is further reduced in GFAPCre+/HIF-1 $\alpha^{+f /+f / H I F-2} \alpha^{+f /+f}$ animals both in normoxia and hypoxia $(n=9)$. Data represent mean + SEM; Mann-Whitney test. (B) Systemic plasma EPO concentrations in control animals subjected to hypoxia (GFAPCre-; $n=16$ ) are not different compared with those of hypoxic GFAPCre+/HIF-1 $\alpha^{+f /+f}$ mice $(n=10)$. In contrast, plasma EPO concentration in hypoxic GFAPCre+/HIF- $2 \alpha^{+f /+f}(n=11)$ and hypoxic GFAP$\mathrm{Cre}+/ \mathrm{HIF}-1 \alpha^{+f /+f / H I F-2} \alpha^{+f /+f}$ mice $(n=8)$ is significantly reduced. Data represent mean + SEM. (C and D) Hypoxic upregulation of EPO mRNA is intact in major EPO-producing tissues in GFAPCre-positive mice: in livers (C), EPO mRNA induction is not significantly different between genotypes (GFAPCre- normoxia, $n=14$; GFAPCre- hypoxia, $n=18$; GFAPCre $+/ \mathrm{HIF}-1 \alpha^{+f /+f}$ hypoxia, $n=8$; GFAPCre+/HIF-2 $\alpha^{+f /+f}$ hypoxia, $n=9$; GFAPCre+/HIF-1 $\alpha^{+f /+f / H I F-2} \alpha^{+f /+f}, n=10$ ). (D) Accordingly, hypoxic EPO mRNA induction in kidneys is unaltered (GFAPCre- normoxia, $n=6$; GFAPCre- hypoxia, $n=15$; GFAPCre+/HIF- $1 \alpha^{+f /+f}$ hypoxia, $n=6$; GFAPCre+/HIF-2 $\alpha^{+f /+f}$ hypoxia, $n=10 ;$ GFAPCre+/HIF-1 $\alpha^{+f /+f / H I F-2} \alpha^{+f /+f}$ hypoxia, $n=11$ ). Data represent mean + SEM.

Ter119) induced by anemia in spleen and bone marrow was analyzed by flow cytometry in WT mice, GFAPCre-negative (GFAPCre-) mice, and mice with Cre expression in astrocytes and therefore lacking the conditional allele (i.e., GFAPCre $+/ \mathrm{HIF}-2 \alpha^{+\mathrm{f} /+f}$ ). The increase of CD71 1 hi $/$ Ter119pos erythroid progenitor cells was significantly reduced in the bone marrow (from $1.25 \pm 0.04$-fold to $1.08 \pm 0.03$-fold) and in the spleen (from $2.420 \pm 0.24$-fold to $1.778 \pm 0.08$-fold; Figure $6, \mathrm{~B}$ and C) of GFAPCre + HIF- $2 \alpha^{+\mathrm{f} / \mathrm{f}}$ mutant animals. Moreover, the reticulocyte number in the peripheral blood was also reduced significantly, by approximately onethird, in the GFAPCre + HIF- $2 \alpha^{+\mathrm{f} / \mathrm{f}}$ mice 72 hours after bleeding $(5.58 \% \pm 0.35 \%$ vs. $8.43 \% \pm 0.89 \%$; Figure $6 \mathrm{D})$.
Taken together, these data demonstrate that in acute stress, astrocyte-derived EPO is a critical contributor to the systemic pool of circulating plasma EPO and that this contribution plays an essential role in stress-induced erythropoiesis.

\section{Discussion}

Historically, the systemic effects of EPO produced in the CNS have been thought to be negligible, except for rare cases of neurogenic polycythemia, which have generally been based on incidences of cerebellar hemangioblastomas (30-32). Interestingly, though, at least one case exists in the literature in which polycythemia coincided with an astrocyte-derived tumor (i.e., a glioblastoma) (33). 

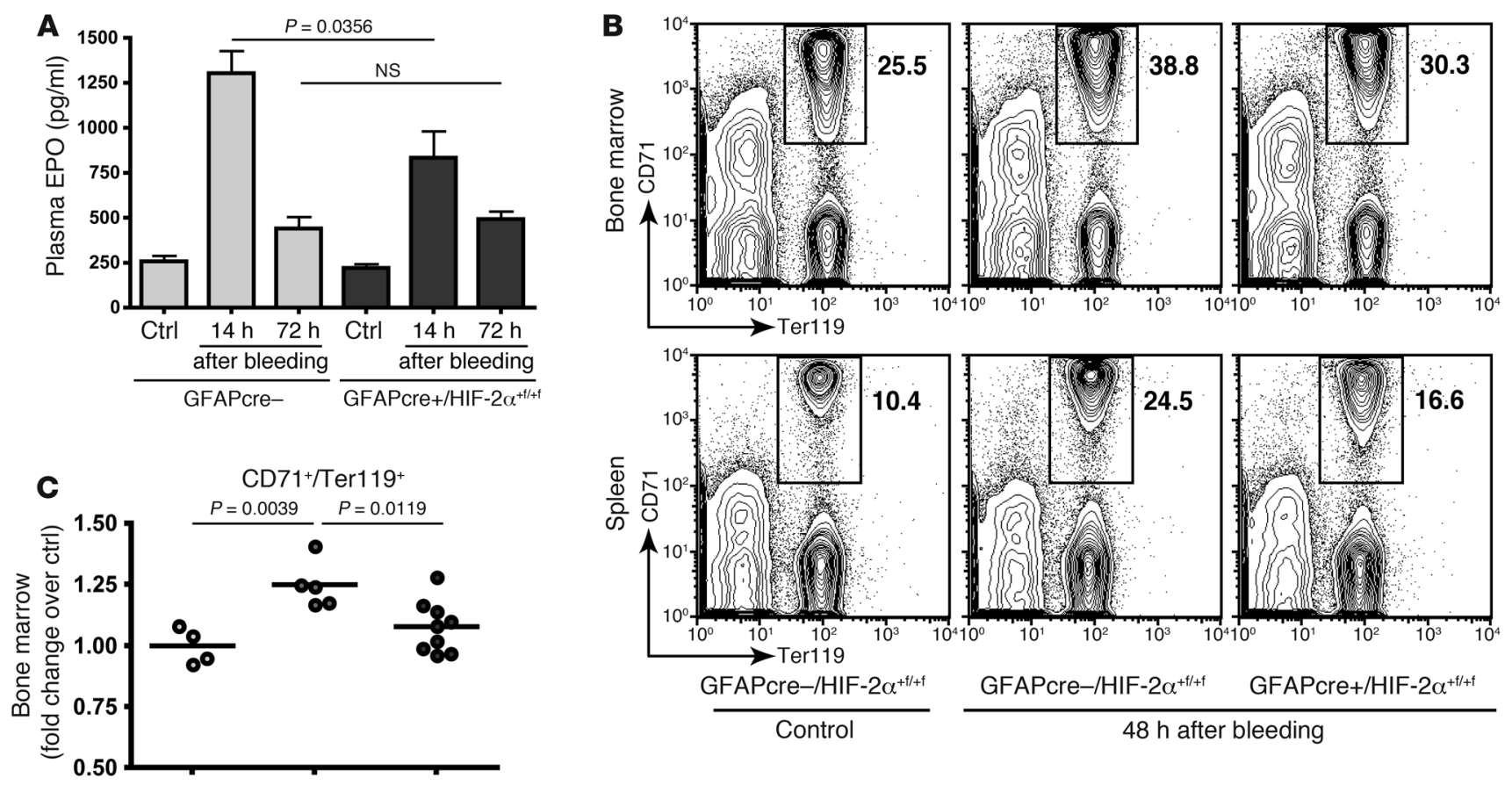

D
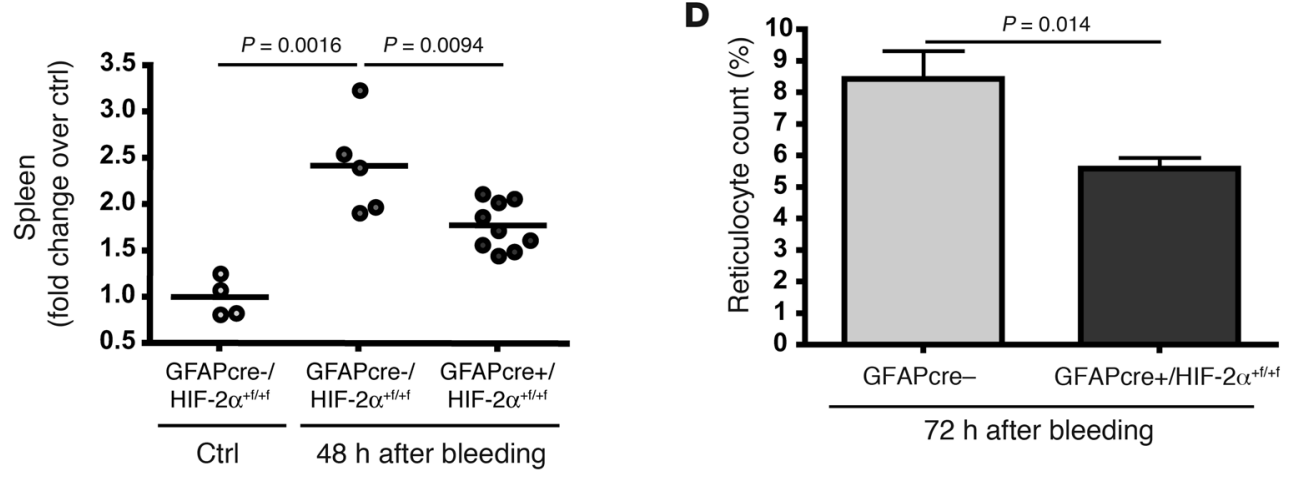

Figure 6

Targeted deletion of HIF-2 $\alpha$ in astrocytes reduces systemic erythropoietic response after bleeding in mice. (A) Plasma EPO concentrations of GFAPCre+/HIF-2 $\alpha^{+f /+f}$ mice $(n=6)$ are significantly lower than in WT animals 24 hours after bleeding (GFAPCre-; $\left.n=6\right)$. 72 hours after bleeding, plasma EPO levels are no longer significantly different. Data represent mean + SEM. (B) Representative flow cytometric experiment of total bone marrow cells (upper) and total splenic cells (lower) of control mice and mice lacking HIF-2 $\alpha$ in astrocytes 48 hours after bleeding. Frequencies (\%) of CD71 ${ }^{\mathrm{hi}} / \mathrm{Ter} 119^{\text {pos }}$ cells in gated fractions are shown. (C) Statistical analysis of the flow cytometry experiment: the frequencies of CD71 hi/Ter119pos erythroid progenitor cells induced by bleeding are significantly less in GFAPCre+/HIF-2 $\alpha^{+f /+f}(n=9) \mathrm{compared}$ with GFAPCre-negative mice $(n=5)$ Data represent mean of fold change over unbled GFAPCre-negative. (D) The reticulocyte counts in peripheral blood 72 hours after bleeding are significantly lower in GFAPCre+/HIF-2 $\alpha^{+f /+f}$ mice $(n=8)$ compared with GFAPCre-negative animals $(n=7)$. Data represent mean + SEM; Mann-Whitney test.

There have been a number of attempts to tie induction of erythropoiesis to the CNS. One series of experiments in the early $1960 \mathrm{~s}$ induced erythropoiesis by "cerebral stimulation" in rabbits (34) and in cats and dogs (35); a significant fraction of the animals developed reticulocytosis in these experiments. Interestingly, a carefully investigated case report of actual erythrocytosis caused by a transient occlusion of the middle cerebral artery further supports a model for CNS-derived EPO acting systemically (36).

We describe here evidence that astrocyte-derived EPO contributes to a systemic erythropoietic response and that this occurs in a HIF- $\alpha$-dependent fashion. We first show that deletion of the VHL gene in astrocytes leads to a HIF- $2 \alpha$-driven pathologic erythrocy- tosis, which is correlated with an endogenous overproduction of $\mathrm{EPO}$ in the CNS. We then demonstrate that loss of HIF- $\alpha$ response in astrocytes reduces systemic plasma EPO concentrations by as much as half, after both hypoxia and blood loss. And, correlated with lower circulating plasma EPO after blood loss, the increase of erythroid progenitors in both spleen and bone marrow is blunted after loss of HIF- $2 \alpha$ in astrocytes.

Deletion of VHL in astrocytes induces a severe pathology with gross macroscopic defects such as hydrocephalus, an exaggerated EPO mRNA induction that drives polycythemia, and reduced survival. Interestingly, the nonhematological aspects of the phenotype precede the polycythemia, which indicates distinct pathoge- 
netic entities. It has previously been shown in other mouse models that polycythemia typically develops after the first 4 to 5 weeks after birth $(37,38)$, potentially due to an inability of the immature bone marrow and spleen to fully respond to hyperstimulation by elevated EPO concentrations.

The premature death in mice with a conditional deletion of VHL in astrocytes is most likely a combination of the various factors investigated here. Although this extensive pathology does not recapitulate human VHL disease, it constitutes an important model for studying pathologic effects of HIF- $\alpha$ overexpression in the CNS. We show that in the CNS and in the absence of neoplasms, the phenotype generated by loss of VHL is mainly dependent on the overexpression of HIF- $2 \alpha$, and not HIF- $1 \alpha$. Moreover, double deletion of VHL and VEGF demonstrates that many of the phenotypic changes are VEGF dependent, acting through HIF- $2 \alpha$ signaling.

In the CNS, EPO is produced in neurons and in astrocytes $(15,16)$. Current models argue that CNS-derived EPO is essential for neuronal development and localized protective effects (12). However, there are indications for crosstalk between peripherally administered EPO and the CNS (13) that argue for movement of EPO across the BBB (39). Our findings provide evidence that this movement is not only unidirectional, but also that efflux of CNS-derived EPO occurs. Indeed, in mice with conditional deletion of VHL in astrocytes, the elevation of EPO levels results in suppression of renal EPO expression, potentially by the elevated hematocrit $(40,41)$.

Although the data presented here indicate that astrocyte EPO is predominantly regulated by HIF- $2 \alpha$, HIF- $1 \alpha$ can also contribute to induction of the response during hypoxia, at least in the absence of HIF- $2 \alpha$. This is somewhat surprising with respect to reports of in vitro data that demonstrate an exclusive HIF- $2 \alpha$ regulation of EPO in astrocytes (18). However, in anemia, a minor role for HIF-1 $\alpha$ in EPO regulation has been suggested (42), and this highlights the complexity of hypoxic EPO regulation. Additionally, our group has demonstrated a HIF- $1 \alpha$ - and vascular flow-dependent change in EPO production stemming from epidermal deletion of HIF- $1 \alpha$ (43). Although cerebral blood flow (CBF) could be a factor in some of the CNS-dependent changes in EPO seen here, the lack of change in renal or hepatic EPO mRNA levels would argue against a direct effect on those organs' EPO synthesis as an explanation for these observations.

It is intriguing, however, to speculate regarding whether acute changes in CBF might be involved in hypoxic response and EPO generation, since it is known that acute hypoxia and anemia increase $\operatorname{CBF}(44,45)$. Furthermore, there remain mechanistic questions concerning how CNS-derived EPO acts in the systemic erythropoietic response. Our data suggest that the major EPO-producing organs act together to elevate plasma EPO concentration as quickly and effectively as possible. Differential kinetics of EPO mRNA expression in the CNS and kidney have been shown (46) and might explain why we observe reduced EPO concentrations in conditional HIF- $2 \alpha-$ knockout animals as late as 12 hours after the induction of hypoxia or anemia. The lack of difference in EPO concentrations 72 hours after bleeding in both WT and GFAP-HIF- $2 \alpha^{+\mathrm{f} /+\mathrm{f}}$ mice thus argues for contribution of glial EPO primarily in an acute response. Given the intense utilization of oxygen by the brain, a tie to an acute erythropoietic response would fit with a role for a link between CNS EPO release and a functional demand for immediate increases in oxygen transport. The participation of the CNS in erythropoiesis would thus occur during acute states in which there is a need for maxi- mal participation of all tissues for induction of EPO (an "all hands on deck" response). An important question to address in the future would be why increased renal or hepatic response cannot accomplish this; another is what advantage a third source of plasma EPO confers on the hypoxic organism.

In conclusion, we have shown here through gain-of-function and loss-of-function mutations in mice that approximately half of the systemic plasma EPO increase following acute hypoxic insult is dependent on a HIF- $\alpha$-driven astrocytic response. Given that HIF mediates the increases in plasma EPO that we have described, these findings also demonstrate that compounds that activate HIF could potentially induce EPO expression in the brain, which in turn could act to increase erythropoiesis independently of renal function.

\section{Methods}

Transgenic mice. All procedures involving animals were approved by the UCSD Animal Care Committee, which serves to ensure that all US government guidelines concerning animal experimentation are met. Generation of mice carrying the loxP-flanked conditional alleles of HIF-1 $\alpha$, HIF-2 $\alpha$, VEGF, and VHL was described previously (21-23, 29). Astrocytespecific inactivation was achieved by cross-breeding those mice to GFAPCre transgenic mice (provided by D. Guttman, Washington University, St. Louis, Missouri, USA; ref. 20) in C57BL/6 background or the respective double knockouts (VHL/HIF-1 $\alpha$, VHL/HIF- $2 \alpha$, and VHL/VEGF) in mixed background. Cre-negative homozygous littermates for the conditional alleles were used as controls. Animals were between 10 and 14 weeks at the time of the experiments.

Hypoxia exposure and bleeding anemia. Animals were exposed to $7.5 \%$ oxygen for 10 hours in a hypoxic animal chamber (BioSpherix Ltd.) and sacrificed immediately thereafter. $180 \mu \mathrm{l}$ blood was taken from anesthetized mice via retroorbital bleeding, and animals were sacrificed after either 14 hours, 48 hours, or 72 hours.

Hematological analysis. Hematocrit analysis was performed in heparinized blood tubes (Fisher Biosciences) after centrifugation according to the manufacturer's protocol. Other hematological parameters were analyzed in the UCSD Animal Care Program Diagnostic Laboratory. For reticulocyte count, blood smears of 1:1 diluted blood with new methylene blue were analyzed. To reduce counting errors, 10 random fields with over 100 blood cells each were counted per animal.

DNA recombination analysis. DNA from tissue was extracted with QIAGEN DNEasy kit according to the manufacturer's protocol. $25 \mathrm{ng}$ of genomic DNA of brain, liver, and kidney was amplified by PCR with primers specific for WT and floxed alleles. Primer sequences are in Supplemental Methods. PCR products were visualized on $2.5 \%$ agarose gels containing $0.005 \%$ ethidium bromide (Sigma-Aldrich).

$R N A$ analysis by reverse transcription and real-time quantitative $P C R$. Total RNA was isolated with TRIzol reagent (Invitrogen) from homogenized tissue. First-strand synthesis was performed with $1 \mu \mathrm{g}$ of total RNA by the SuperScript System (Invitrogen) according to the manufacturer's protocol. For real-time PCR analyses, cDNAs were diluted to a final concentration of $5 \mathrm{ng} / \mu \mathrm{l}$ (for EPO) or $1 \mathrm{ng} / \mu \mathrm{l}$ (other HIF-target genes) and amplified in SYBR Green or TaqMan Universal Master Mix (Applied Biosystems) with an ABI PRISM 7700 sequence detection system (Applied Biosystems). Expression levels were related to $18 \mathrm{~S}$ using the $\Delta \mathrm{Ct}$ method. Primer sequences are in Supplemental Methods.

Immunohistochemistry. Mice were transcardially perfused with PBS containing $0.5 \mathrm{mM}$ EDTA followed by $4 \%$ PBS-buffered paraformaldehyde (SigmaAldrich), and tissue was embedded in paraffin. HIF immunohistochemistry was done as described before (47). For other stainings, $5 \mu \mathrm{m}$ sections were subjected to microwave antigen retrieval with citrate buffer and 
immunohistochemistry (Vector Elite Peroxidase Kit; Vector Laboratories) or immunofluorescence. The following primary antibodies were used: CD34 (Novus), Cre (Novagen), GFAP (DAKO), and NeuN (Millipore). Secondary antibodies for immunohistochemistry were from Santa Cruz Biotechnology Inc., and those for immunofluorescence were from Molecular Probes. DAPI was purchased from Sigma-Aldrich. For Nissl staining, sections were stained in $0.1 \%$ cresyl violet.

EPO ELISA. EPO protein in blood plasma was determined using the Quantikine Mouse EPO ELISA kit (R\&D Systems) according to manufacturer's protocol.

Western blot analysis. Snap-frozen tissue was homogenized in buffer A (10 mM Tris, pH 8, 1 mM EDTA, pH 8, 150 mM NaCl, 0.5\% NP 40, 1 mM PMSF; all from Sigma-Aldrich; and complete PI tablets; Roche) to yield cytoplasmic protein. Nuclear proteins were extracted in buffer C $(20 \mathrm{mM}$ Hepes, pH 7.9, $400 \mathrm{mM} \mathrm{NaCl}, 1 \mathrm{mM}$ EDTA, pH 8, 1 mM DTT, $1 \mathrm{mM}$ PMSF). $30 \mu$ g of nuclear protein was separated on $4 \%-8 \%$ Tris-Acetate Gels (Invitrogen) followed by immunoblotting as described (48). Primary antibodies for HIF- $1 \alpha$ and HIF- $2 \alpha$ were from Novus Biologicals. Equal loading was documented by Coomassie staining.

$f M R I$. The mice were imaged in vivo under isoflurane anesthesia using a Bruker 7 Tesla small animal magnetic resonance imaging scanner. The images were acquired with a 1.5 -cm custom-built surface MRI coil, which was manually tuned. T1 and T2 weighted images were acquired using a rapid acquisition with relaxation enhancement (RARE) pulse sequence as follows: field of view, $2 \mathrm{~cm}$, matrix $256 \times 200$ with a slice thickness of 300 microns, flip angle, 180 degrees. T1 parameters were as follows: echo time/ repetition time (TE/TR) 7.1/3358 ms, 6 averages. T2 parameters were as follows: TE/TR 35.2/16716 ms, 4 averages.

2-Photon microscopy. Images were collected using a 2-photon laser scanning microscope of custom design (49) that was controlled by MPScope software (50). The blood serum was labeled using $0.1 \mathrm{ml}$ of $2 \mathrm{MDa}$ fluorescein dextran (FD2000S; Sigma-Aldrich) prepared at a concentration of $2.5 \%(\mathrm{w} / \mathrm{v})$ in physiological saline and delivered through a tail-vein injection with $0.1 \mathrm{ml}$ supplements as required. A 0.5 numerical aperture (NA), $\times 20$ magnification water-dipping objective was used to collect large-scale image stacks of surface vasculature, whereas a 0.8 -NA, $\times 40$ magnification water-dipping objective (both Olympus) was used to obtain high-resolution line scan and planar data. The line scans were collected along the center line of each vessel over a length of 500 pixels at a scan rate of 1.6 $\mathrm{kHz} /$ line. Red blood cell velocity was determined using a method based on the Radon transform (51). Planar image stacks, $256 \times 256$ pixels, were acquired to establish the diameter of the vessel. A median filter (radius, 1 pixel) was applied to each image to reduce background noise.

$B B B$ permeability assay with Evans blue. Evans blue (EB) leakage into the CNS was measured essentially as previously described (52). EB (SigmaAldrich) was injected intraperitoneally (50 $\mathrm{g} / \mathrm{g}$ body weight), and 3 hours later mice were sacrificed and perfused intracardially with $20 \mathrm{ml}$ PBS to remove intravascular EB; brain was collected and weighed. The specimens were extracted in $3 \mathrm{ml}$ pure formamide (Sigma-Aldrich) for 72 hours, and OD was measured at $620 \mathrm{~nm}$.

Flow cytometry. Mice were sacrificed 48 hours after bleeding, and single-cell suspensions were prepared from bone marrow (femur/tibia) and spleen. After washing with PBS, cells were incubated for 15 minutes at $4{ }^{\circ} \mathrm{C}$ with Fcg receptor blocking antibody (2.4G2; eBioscience) in PBS containing $1 \%$ FCS, $2 \mathrm{mM} \mathrm{EDTA}$, and $0.01 \% \mathrm{NaN}_{3}$. Cells were then stained for 15 minutes at $4^{\circ} \mathrm{C}$ with anti-mouse $\mathrm{CD} 71$ (clone 17217; eBioscience) and anti-mouse Ter119 (clone TER119; eBioscience) as well as 7-aminoactinomycin D (7-AAD) (Invitrogen) for exclusion of dead cells; they were subsequently analyzed on a FACScalibur (BD Biosciences). Data were analyzed with FlowJo software (Tree Star). Profiles are presented as 5\% probability contours with outliers.

Statistics. All statistic analysis was performed using Prism (GraphPad Software). Unless otherwise indicated, a 2-sided unpaired Student's $t$ test was used for the analysis of differences in mean values between groups. Significance was defined as $P<0.05$.

\section{Acknowledgments}

A. Weidemann was supported by a fellowship of the German Research Foundation (DFG WE4275/1-1). C. Stockmann was supported by a fellowship of the German Research Foundation (STO 787/1-1). We thank J. Choi and M. Salcedo for technical assistance. We thank D. Liao, B. Blouw, P. Blinder, B. Friedmann, C. Schachtrup, N. Zhang, C. Warnecke, M. Wiesener, and K.U. Eckardt for technical advice, helpful conversations, and discussions.

Received for publication March 30, 2009, and accepted in revised form August 5, 2009.

Address correspondence to: Randall S. Johnson, Division of Biology, University of California, San Diego, 9500 Gilman Drive, La Jolla, California 92093, USA. Phone: (858) 822-0509; Fax: (858) 822-5833; E-mail: rsjohnson@ucsd.edu.
1. Jelkmann, W. 1992. Erythropoietin: structure, control of production, and function. Physiol. Rev. 72:449-489.

2. Viault, F. 1890. Sur l'augmentation considerable du nombre des globules rouges dans le sang chez le habitants des hautes plateaux de l'Amerique du Sud. C.R. Acad. Sci. Paris. 111:918-919.

3. Semenza, G.L., and Wang, G.L. 1992. A nuclear factor induced by hypoxia via de novo protein synthesis binds to the human erythropoietin gene enhancer at a site required for transcriptional activation. Mol. Cell. Biol. 12:5447-5454.

4. Weidemann, A., and Johnson, R.S. 2008. Biology of HIF-1alpha. Cell Death Differ. 15:621-627.

5. Wenger, R.H. 2002. Cellular adaptation to hypoxia: $\mathrm{O} 2$-sensing protein hydroxylases, hypoxia-inducible transcription factors, and O2-regulated gene expression. FASEB J. 16:1151-1162.

6. Maxwell, P.H., et al. 1999. The tumour suppressor protein VHL targets hypoxia-inducible factors for oxygen-dependent proteolysis. Nature. 399:271-275.

7. Fandrey,J. 2004. Oxygen-dependent and tissue-specific regulation of erythropoietin gene expression. Am.J.
Physiol. Regul. Integr. Comp. Physiol. 286:R977-R988.

8. Weidemann, A., and Johnson, R.S. 2009. Nonrenal regulation of EPO synthesis. Kidney Int. 75:682-688.

9. Jacobson, L.O., Goldwasser, E., Fried, W., and Plzak, L. 1957. Role of the kidney in erythopoiesis. Nature. 179:633.

10. Carnot, P., and Deflandre, C. 1906. Sur l'activité hémopoiétique des différents organes au cours de la régénération du sang. C. $R$. Acad. Sci. Paris. 143:432-435

11. Tan, C.C., Eckardt, K.U., Firth, J.D., and Ratcliffe, P.J. 1992. Feedback modulation of renal and hepatic erythropoietin mRNA in response to graded anemia and hypoxia. Am. J. Physiol. 263:F474-F481.

12. Dame, C., Juul, S.E., and Christensen, R.D. 2001. The biology of erythropoietin in the central nervous system and its neurotrophic and neuroprotective potential. Biol. Neonate. 79:228-235.

13. Brines, M.L., et al. 2000. Erythropoietin crosses the blood-brain barrier to protect against experimental brain injury. Proc. Natl. Acad. Sci. U. S. A. 97:10526-10531.

14. Marti, H.H. 2004. Erythropoietin and the hypoxic brain. J. Exp. Biol. 207:3233-3242.

15. Bernaudin, M., et al. 2000. Neurons and astrocytes express EPO mRNA: oxygen-sensing mechanisms that involve the redox-state of the brain. Glia. 30:271-278.

16. Masuda, S., et al. 1994. A novel site of erythropoietin production. Oxygen-dependent production in cultured rat astrocytes. J. Biol. Chem. 269:19488-19493.

17. Marti, H.H., et al. 1996. Erythropoietin gene expression in human, monkey and murine brain. Eur. J. Neurosci. 8:666-676.

18. Chavez, J.C., Baranova, O., Lin, J., and Pichiule, P. 2006. The transcriptional activator hypoxia inducible factor 2 (HIF-2/EPAS-1) regulates the oxygendependent expression of erythropoietin in cortical astrocytes. J. Neurosci. 26:9471-9481.

19. Rossi, D.J., Brady, J.D., and Mohr, C. 2007. Astrocyte metabolism and signaling during brain ischemia. Nat. Neurosci. 10:1377-1386.

20. Bajenaru, M.L., et al. 2002. Astrocyte-specific inactivation of the neurofibromatosis 1 gene (NF1) is insufficient for astrocytoma formation. Mol. Cell. Biol. 22:5100-5113. 
21. Ryan, H.E., Lo, J., and Johnson, R.S. 1998. HIF-1 alpha is required for solid tumor formation and embryonic vascularization. EMBOJ. 17:3005-3015.

22. Gruber, M., et al. 2007. Acute postnatal ablation of Hif-2alpha results in anemia. Proc. Natl. Acad. Sci. U. S. A. 104:2301-2306.

23. Haase, V.H., Glickman, J.N., Socolovsky, M., and Jaenisch, R. 2001. Vascular tumors in livers with targeted inactivation of the von Hippel-Lindau tumor suppressor. Proc. Natl. Acad. Sci. U. S. A. 98:1583-1588.

24. Kondo, K., Klco, J., Nakamura, E., Lechpammer, M., and Kaelin, W.G., Jr. 2002. Inhibition of HIF is necessary for tumor suppression by the von Hippel-Lindau protein. Cancer Cell. 1:237-246.

25. Maranchie, J.K., et al. 2002. The contribution of VHL substrate binding and HIF1-alpha to the phenotype of VHL loss in renal cell carcinoma. Cancer Cell. 1:247-255.

26. Kondo, K., Kim, W.Y., Lechpammer, M., and Kaelin, W.G., Jr. 2003. Inhibition of HIF2alpha is sufficient to suppress PVHL-defective tumor growth. PLoS Biol. 1:E83.

27. Rankin, E.B., et al. 2008. Hypoxia-inducible factor-2 regulates vascular tumorigenesis in mice. Oncogene. 27:5354-5358.

28. Brodsky, I., Dennis, L.H., Kahn, S.B., and Brady, L.W. 1966. Normal mouse erythropoiesis. I. The role of the spleen in mouse erythropoiesis. Cancer Res. 26:198-201.

29. Gerber, H.P., et al. 1999. VEGF is required for growth and survival in neonatal mice. Development. 126:1149-1159.

30. Cramer, F., and Kimsey, M.W. 1952. The cerebellar hemangioblastomas; review of fifty-three cases with special reference to cerebellar cysts and the association of polycythemia. AMA Arch. Neurol. Psychiatry. 67:237-252.

31. Waldmann, T.A., Levin, E.H., and Baldwin, M. 1961. The association of polycythemia with a cerebellar hemangioblastoma. The production of an erythro- poiesis stimulating factor by the tumor. Am.J. Med. 31:318-324.

32. Kuhne, M., Sidler, D., Hofer, S., Lugli, A., and Ludwig, C. 2004. Challenging manifestations of malignancies. Case 1 . Polycythemia and high serum erythropoietin level as a result of hemangioblastoma. J. Clin. Oncol. 22:3639-3640.

33. Lecuire, J., et al. 1972. Left temporal glioblastoma associated with polyglobulia [In French]. J. Med. Lyon. 53:559-563.

34. Seip, M., Halvorsen, S., Andersen, P., and Kaada, B.R. 1961. Effects of hypothalamic stimulation on erythropoiesis in rabbits. Scand. J. Clin. Lab. Invest. 13:553-563.

35. Kell, J.F., Jr., Hoff, E.C., and Hennigar, G.R. 1960. Erythrocytosis or symptomatic polycythemia following chronic cerebral stimulation through indwelling electrodes. J. Neurosurg. 17:1028-1038.

36. Gilbert, H.S., and Silverstein, A. 1965. Neurogenic polycythemia. Report of a patient with transient erythrocytosis associated with occlusion of a middle cerebral artery, and review of the literature. $A m$. J. Med. 38:807-813.

37. Divoky, V., et al. 2001. Mouse model of congenital polycythemia: Homologous replacement of murine gene by mutant human erythropoietin receptor gene. Proc. Natl. Acad. Sci. U. S. A. 98:986-991.

38. Wagner, K.F., et al. 2001. Chronic inborn erythrocytosis leads to cardiac dysfunction and premature death in mice overexpressing erythropoietin. Blood. 97:536-542.

39. Banks, W.A., et al. 2004. Passage of erythropoietic agents across the blood-brain barrier: a comparison of human and murine erythropoietin and the analog darbepoetin alfa. Eur. J. Pharmacol. 505:93-101.

40. Kilbridge, T.M., Fried, W., and Heller, P. 1969. The mechanism by which plethora suppresses erythropoiesis. Blood. 33:104-113.

41. Necas, E., Zivny, J., and Neuwirt, J. 1972. Effect of polycythemia on erythropoietin production in the hypoxic rat. Am. J. Physiol. 223:809-811.
42. Rankin, E.B., et al. 2007. Hypoxia-inducible factor-2 (HIF-2) regulates hepatic erythropoietin in vivo. J. Clin. Invest. 117:1068-1077.

43. Boutin, A.T., et al. 2008. Epidermal sensing of oxygen is essential for systemic hypoxic response. Cell. 133:223-234.

44. Jones, M.D., Jr., Traystman, R.J., Simmons, M.A., and Molteni, R.A. 1981. Effects of changes in arterial $\mathrm{O} 2$ content on cerebral blood flow in the lamb. Am. J. Physiol. 240:H209-H215.

45. Ulatowski, J.A., Bucci, E., Razynska, A., Traystman, R.J., and Koehler, R.C. 1998. Cerebral blood flow during hypoxic hypoxia with plasma-based hemoglobin at reduced hematocrit. Am. J. Physiol. 274:H1933-H1942.

46. Chikuma, M., Masuda, S., Kobayashi, T., Nagao, M., and Sasaki, R. 2000. Tissue-specific regulation of erythropoietin production in the murine kidney, brain, and uterus. Am. J. Physiol. Endocrinol. Metab. 279:E1242-E1248.

47. Weidemann, A., et al. 2008. HIF activation protects from acute kidney injury. J. Am. Soc. Nephrol. 19:486-494.

48. Weidemann, A., et al. 2008. Hypoxia, via stabilization of the hypoxia-inducible factor HIF-1alpha, is a direct and sufficient stimulus for brain-type natriuretic peptide induction. Biochem. J. 409:233-242.

49. Tsai, P.S., et al. 2003. All-optical histology using ultrashort laser pulses. Neuron. 39:27-41.

50. Nguyen, Q.T., Tsai, P.S., and Kleinfeld, D. 2006. MPScope: a versatile software suite for multiphoton microscopy. J. Neurosci. Methods. 156:351-359.

51. Drew, P.J., Blinder, P., Cauwenberghs, G., Shih, A.Y., and Kleinfeld, D. 2009. Rapid determination of particle velocity from space-time images using the Radon transform. J. Comput. Neurosci. Online publication ahead of print. doi:10.1007/s10827009-0159-1.

52. Methia, N., et al. 2001. ApoE deficiency compromises the blood brain barrier especially after injury. Mol. Med. 7:810-815. 